\title{
Spectroscopic and Photophysical Studies of Fingerprint Dusting Compositions
}

Keywords: Fingerprints; Fluorescence; Fourier transform infrared spectroscopy; Photophysical parameters; UV-visible spectra

\begin{abstract}
The two fingerprint dusting compositions considered here were based on fluorescent brilliant blue $R$ and acridine orange stains. The bonding material in each case was a combination of silica gel and hydrated magnesium silicate. Spectral and photochemical studies revealed that the compositions were not merely physical mixtures of bonding material and colorant but the constituents interact chemically with each other, profoundly affecting the quality of developed prints.
\end{abstract}

\section{Introduction}

Regular fingerprint powders consist of coloured particles, each of which is bonded with a resinous polymer; the coloured particle provides contrast and the polymer coating provides adhesion [1]. It is commonly perceived that in a fingerprint dusting compositions, the two components act independently of each other. The adhesive gets adhered to the moisture and oily component of sweat residue by the mechanism of which are treated by G.L. Thomas, while the colorant gets adsorbed on the adhesive [2].

Luminescent powders are advantageous as these can develop prints with a good contrast on multicoloured surfaces [3,4]. Moreover, these assist detection of weak, accidental finger impressions that are often found at crime scenes.

The application of finely divided material and subsequent removal of the excess powder by brushing, blowing or tapping has been the universal method of developing fingerprints on an array of surfaces [5]. The technique relies on the chemical adherence of fingerprint powder to the moisture and oily components of skin ridge deposit [6]

In continuation to our interest in investigating the application of fluorescent dusting formulations to detection of latent fingerprints $[7,8]$, we reported in this communication, two powder compositions incorporating a bonding material mixture of silica gel (major) and hydrated magnesium silicate (minor). Brilliant blue $\mathrm{R}$ is the colorant in one composition, acridine orange in the other. On the basis of spectral and photophysical studies, we concluded that the mixture and the colorant were not independent entities. These were interacted with each other, as a result of which the quality of developed fingerprints was profoundly affected.

\section{Experimental Methods}

Brilliant blue R, acridine orange and silica gel (mesh size 100-200) were procured from Sigma-Aldrich and were used without further purification. Commercial grade hydrated magnesium silicate was used.

The following instruments were used: SPECTRUM RX I (Perkin

\section{Forensic Investigation}

\author{
Smily Kapoor ${ }^{1 *}$, Gurvinder S. Sodhi ${ }^{2}$ and Sanjiv \\ Kumar $^{3}$ \\ ${ }^{\text {I} U n i v e r s i t y ~ S c i e n c e ~ I n s t r u m e n t a t i o n ~ C e n t e r, ~ U n i v e r s i t y ~ o f ~ D e l h i, ~ D e l h i, ~}$ \\ India \\ ${ }^{2}$ Forensic Science Unit, S.G.T.B. Khalsa College, University of Delhi, \\ India \\ ${ }^{3}$ Department of Chemistry, Indira Gandhi National Open University, \\ Maidan Garhi, New Delhi, India
}

\section{*Address for Correspondence}

Smily Kapoor, University Science Instrumentation Center, University of Delhi, Delhi, India, Tel: +91 9873115130; E-mail: smily248@gmail.com

Submission: 18 August, 2015

Accepted: 4 November, 2015

Published: 8 November, 2015

Copyright: (๑) 2015 Kapoor S, et al. This is an open access article distributed under the Creative Commons Attribution License, which permits unrestricted use, distribution, and reproduction in any medium, provided the original work is properly cited.

Reviewed \& Approved by: Dr. Ali Kocak, Associate Professor, John Jay College of Criminal Justice, USA

Elmer), collecting eight scans from $400-4000 \mathrm{~cm}^{-1}$, with a resolution of $4 \mathrm{~cm}^{-1}$ for Fourier Transform Infrared studies; Shimadzu Model UV 1600 spectrophotometer for recording Ultraviolet Visible spectra; Jobon Yvon Horiba Fluorolog Fluorimeter for fluorescence studies.

The curve for fluorescence spectra was obtained by setting the excitation wavelength to be the absorption maximum. Corrected fluorescence spectra of the two soluble dyes were obtained using a high pressure Xenon flash lamp as excitation source. The light path was $1 \mathrm{~cm}$ in all spectral recordings. Rhodamine B in ethanol (Quantum yield for fluorescence, $\Phi_{\mathrm{f}}=0.65$ ) was used as a standard. All spectra were recorded in ethanol at a concentration of about $10^{-4}$ $\mathrm{mol} / \mathrm{L}$.

Twenty five students and faculty members of our group, in the age group of 20 to 50 years, with variable donor capabilities were asked to impinge latent fingerprints on different porous and non porous surfaces by mild pressure, without prior washing and cleaning of hands. This ensured practical variability in the print samples. The entire project was conducted in winter season when the temperature was $18-20^{\circ} \mathrm{C}$ and relative humidity $30-75 \%$.

\section{Surfaces considered}

The compositions were tested on both absorbent (porous) and non-absorbent (non-porous) items. The absorbent surfaces used were xerox paper, newspaper and glossy paper. The non-absorbent surfaces were glass, lamination sheet and metal.

The quality of developed fingerprints was gauged on the basis of ridge clarity and degree of fluorescence, on a scale ranging from zero to 10 , according to the criteria generally followed in India [9], as summarized in Table 1.

Procedure: To a mixture of silica gel $(4.0 \mathrm{~g})$ and hydrated 
Citation: Kapoor S, Gurvinder S. Sodhi, Kumar S. Spectroscopic and Photophysical Studies of Fingerprint Dusting Compositions. J Forensic Investigation. 2015;3(2): 4 .

ISSN: 2330-0396

Table 1: Grading of developed fingerprints

\begin{tabular}{|c|r|}
\hline Grade & Ridge characteristics \\
\hline 10 & Good fluorescence, clear ridges, no background noise \\
\hline 9 & Poor fluorescence, clear ridges, light background noise \\
\hline 8 & Good fluorescence, clear ridges, substantial background noise \\
\hline 7 & Poor fluorescence, clear ridges but background smudging \\
\hline 6 & Poor fluorescence, clear ridges but lack of contrast \\
\hline 5 & Only a few clear ridges, background noise \\
\hline 4 & Only a few ridge characters identifiable \\
\hline 3 & Number of ridge characters less than that required for identification \\
\hline 2 & Lack of ridge clarity due to high background noise \\
\hline 1 & Entire print smudged \\
\hline 0 & Prints not developed \\
\hline
\end{tabular}

Table 2: Spectroscopic and photophysical data of pure stains and fingerprint dusting compositions.

\begin{tabular}{|c|c|c|c|c|}
\hline \multirow[t]{2}{*}{ Photophysical parameter } & \multicolumn{2}{|c|}{ Brilliant blue $\mathbf{R}$} & \multicolumn{2}{|c|}{ Acridine orange } \\
\hline & Pure stain & Composition & Pure stain & Composition \\
\hline Quantum yield of fluorescence, $\Phi_{f}$ & 0.644 & 0.686 & 0.739 & 0.718 \\
\hline $\begin{array}{l}\text { Quantum yield of intersystem crossing, } \\
\qquad \Phi_{\text {isc }}\end{array}$ & 0.355 & 0.313 & 0.261 & 0.282 \\
\hline $\begin{array}{l}\text { Quantum yield of internal conversion, } \\
\qquad \Phi_{\text {ic }}\end{array}$ & 0.196 & 0.143 & 0.092 & 0.125 \\
\hline Intrinsic radiative lifetime, $T_{n}$ (ns) & 6.06 & 7.89 & 7.72 & 9.96 \\
\hline Actual radiative lifetime, $\mathrm{T}_{\mathrm{f}}(\mathrm{ns})$ & 3.91 & 5.41 & 5.71 & 7.15 \\
\hline Rate constant for fluorescence, $\mathrm{K}_{\mathrm{f}}\left(\mathrm{ns}^{-1}\right)$ & 0.165 & 0.126 & 0.129 & 0.100 \\
\hline $\begin{array}{l}\text { Rate constant for intersystem crossing, } \\
\qquad \mathrm{K}_{\mathrm{isc}}\left(\mathrm{ns}^{-1}\right)\end{array}$ & 0.091 & 0.058 & 0.045 & 0.039 \\
\hline $\begin{array}{l}\text { Rate constant for internal conversion, } \\
\qquad \mathrm{K}_{\mathrm{ic}}\left(\mathrm{ns}^{-1}\right)\end{array}$ & 0.050 & 0.026 & 0.016 & 0.017 \\
\hline Oscillator strength, $f$ & 0.880 & 0.655 & 0.487 & 0.361 \\
\hline $\begin{array}{l}\text { Einstein's absorption probability, } B_{n m} \\
\left(\times 10^{6}\right)\end{array}$ & 1.038 & 0.780 & 0.566 & 0.427 \\
\hline Einstein's emission probability, $A_{m n}\left(x 10^{6}\right)$ & 0.716 & 0.549 & 0.561 & 0.435 \\
\hline Absorption maxima, $\lambda_{\max (a b s)}(\mathrm{nm})$ & 596 & 587 & 501 & 490 \\
\hline Emission maxima, $\lambda_{\max (e m m)}(\mathrm{nm})$ & 634 & 643 & 625 & 636 \\
\hline Stokes shift $\left(\mathrm{cm}^{-1}\right)$ & 1005.7 & 1483.8 & 3960.0 & 4684.7 \\
\hline
\end{tabular}

magnesium silicate $(0.5 \mathrm{~g})$, a solution containing Brilliant blue $\mathrm{R}(0.02$ g) in distilled water $(10 \mathrm{~mL})$ was added. The contents were stirred vigorously and then allowed to dry at room temperature for 4-7 days. The dried mass was grounded with a motor and pestle and the fine powder was stored in a tightly stopper vessel. The acridine orange based composition was prepared by following the same steps.

Both the compositions were applied to the surfaces impinged with latent fingerprints with a camel hair brush. The extra powder was blown off. The surfaces were photographed using a GE X 5 digital camera in the auto mode. All the photographs were taken with full resolution (14 mega pixels) to capture finer details. The fluorescence of the prints were observed in Cyan Polylight of wavelength $505 \mathrm{~nm}$.
Depletion studies were carried out on glossy paper.

\section{Results and Discussions}

Using the novel formulations, latent fingerprints were developed on a broad spectrum of absorbent and non-absorbent items. Representative cases on Photostat paper and metallic surface were depicted in Figures 1 and 2 respectively. Figure 2 showed a representative fingerprint developed on a metallic surface by Brilliant blue $\mathrm{R}$ and acridine orange based compositions. Figure 3 showed the latent fingerprints under fluorescence light by Brilliant blue $\mathrm{R}$ based composition.

Depletion studies to test the validity of brilliant blue $\mathrm{R}$ based composition were carried out on a plastic item. The finger was wiped on the forehead and four impressions were impinged in succession.

The developed fingerprints were illuminated with radiation having wavelength of 505-550 $\mathrm{nm}$. When observed through red goggles, the fingerprints showed fluorescence.

The quality of developed fingerprints was observed on the basis of ridge clarity and degree of fluorescence, on a scale ranging from 0 to 10 (Table 1). On an average the print develop by brilliant blue $\mathrm{R}$ based composition were assigned a value of 8 while those developed by acridine orange based composition were assigned a grading of 6 . Graph 1 showed an assessment of the effectiveness of two fluorescent powder compositions for latent fingerprint development on different substrates.

\section{Fourier transform infrared spectra}

The infrared spectra obtained by grounding each formulation with $\mathrm{KBr}$ powder (Infrared grade by Merck) and made pellets with the help of hydraulic press, maintained five tonnes of pressure for few seconds. A comparison of FTIR spectra of the pure silica gel, SG-B and SG-A with the vibrational modes of the major peaks was shown in Figure 4. In the infrared spectra of pure silica gel, a prominent and intense absorption occurred at $1050 \mathrm{~cm}^{-1}$ due to (Si-O-Si) antisymmetric vibrations. In the FT-IR spectrum, this absorption split up in a shoulder peak at $1083 \mathrm{~cm}^{-1}$ and a sharp intense peak at $1037 \mathrm{~cm}^{-1}$. The former was assigned to the longitudinal optical mode of Si-O-Si vibrations, the latter to the transverse optical mode [10]. Both these vibrations undergo perturbations in the fingerprint compositions.

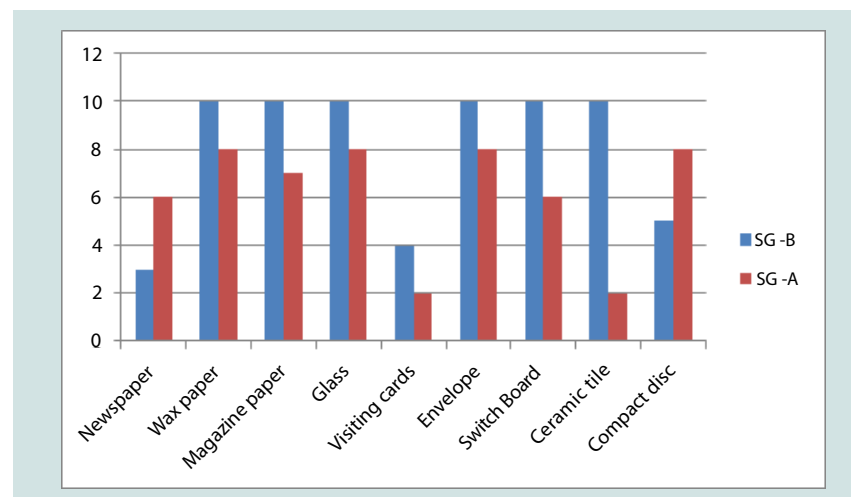

Graph 1: An assessment of the effectiveness of two fluorescent powder compositions for latent fingerprint development on different substrates. 
Citation: Kapoor S, Gurvinder S. Sodhi, Kumar S. Spectroscopic and Photophysical Studies of Fingerprint Dusting Compositions. J Forensic Investigation. 2015;3(2): 4

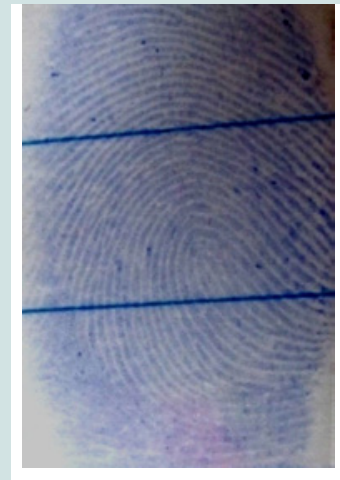

$1(\mathrm{~A})$

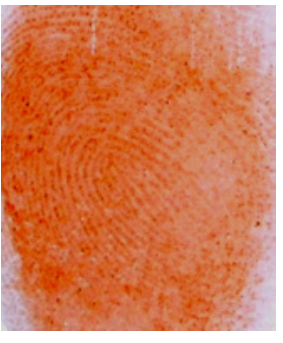

1(B)
Figure 1: Latent fingerprints developed on Photostat paper by (A) Brillian blue $\mathrm{R}$ based composition and $(\mathrm{B})$ acridine orange based composition.

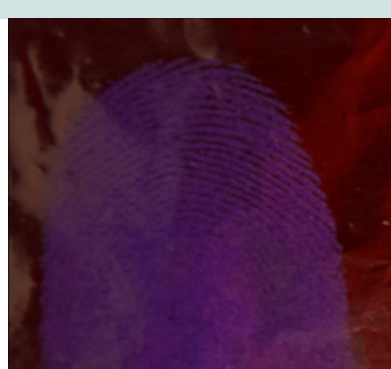

2(A)

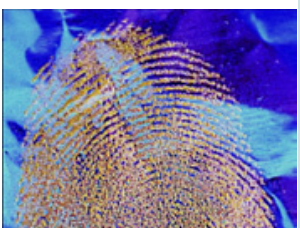

2(B)
Figure 2: Latent fingerprints developed on a metallic surface by $(A)$ brilliant blue $\mathrm{R}$ based composition and $(\mathrm{B})$ acridine orange based composition.

The longitudinal optical mode of Si-O-Si vibrations absorbed at $1053 \mathrm{~cm}^{-1}$, while transverse optical mode absorbed at $1018 \mathrm{~cm}^{-1}$. Moreover, the (Si-O-H) stretching vibration, which occurs at 965 $\mathrm{cm}^{-1}$, completely disappeared in the novel compositions, indicating deprotonation. The absorption band at $670 \mathrm{~cm}^{-1}$, observed in the formulations, was attributed to ( $\mathrm{Mg}-\mathrm{O})$ stretching vibrations, indicating the presence of talc as one of the adhesive materials.

\section{Ultraviolet visible spectra}

All the powder formulations and their individual stains were dissolved in ethanol for ultraviolet visible studies. The brilliant blue $\mathrm{R}$ and acridine orange showed an intense absorption at $596 \mathrm{~nm}$ and 501 $\mathrm{nm}$, respectively, due to $\pi-\pi^{*}$ transitions. In the compositions, these shift to $587 \mathrm{~nm}$ and $490 \mathrm{~nm}$, respectively, although their intensity was not affected [ $\log \varepsilon$ (molar extinction coefficient) calculated. 4.25]. The hypsochromic shift indicated less delocalized electronic structures of the stains and, in turn, implied the interaction of the colorants with a mixture.

\section{Fluorescence spectra}

The photophysical parameters of the fluorescent stains, as well as the fingerprints powder compositions were presented in Table 2. The emission band was observed at a longer wavelength than the absorption band. Thus, in accordance with Franck-Condon principle and thermal relaxation of vibrational modes, the fluorescence spectra was observed on the red side of the absorption band, in an approximately mirror image relationship [11]. The bathochromic shift, in turn, might be attributed to solvation and/or caging effects. The more pronounced stokes shift in the compositions, as compared to those in pure stains, suggested an excited state species that was structurally different from the ground state analog, implying, in turn, a considerable degree of conformational changes in the compositions vis-à-vis the pure strains.

The actual radiative lifetime of the excited state, $\tau_{\mathrm{f}}$ was smaller than the intrinsic radiative lifetime, $\tau_{n}$, indicating the possibility of non-radiating energy dissipation processes depopulating the excited state. Thus fluorescence remained the dominant but certainly not the exclusive mode of emission.

The difference between the actual and intrinsic radiative lifetime was more pronounced in the compositions than in the stains. The acridine orange-based composition had a larger difference than the brilliant blue $\mathrm{R}$ based composition. This meant that in the former case the non-radiative processes that were, intersystem crossing and internal conversion compete with fluorescence to a larger extent than in the later. This was duly reflected in the larger value of Einstein's probability of spontaneous absorption, $B_{n m}$ than the corresponding probability of spontaneous emission, $A_{m n}$ for the brilliant blue $\mathrm{R}$ based formulation. For acridine orange based composition, the value of spontaneous absorption and emission were comparable. The dominance of fluorescence in brilliant blue $\mathrm{R}$ based powder was responsible for better quality fingerprints developed by this composition than those developed by acridine orange based composition.

The quantum yield of fluorescence, intersystem crossing and internal conversion followed the order $\Phi_{\mathrm{f}}>\Phi_{\text {isc }}>\Phi_{\mathrm{ic}}$. Their priorities were also established by their respective rate constants [12].

The oscillator strength, $f$ had been calculated from the relation $f=4.31^{\star} 10^{-9} \int \varepsilon\left(v^{-}\right) \mathrm{d} v^{-}$which was valid if we assumed a Lorenzian shape for the absorption band. The factor $\int \varepsilon\left(v^{-}\right) \mathrm{d} v^{-}$was replaced by $\varepsilon_{\max } \Delta v^{-}$where $\Delta v^{-}$was the half band width of the absorption band [13]. The greater value of oscillator strength of brilliant blue $\mathrm{R}$ based composition as compared to the acridine orange based composition was also a factor contributing to the better quality of developed

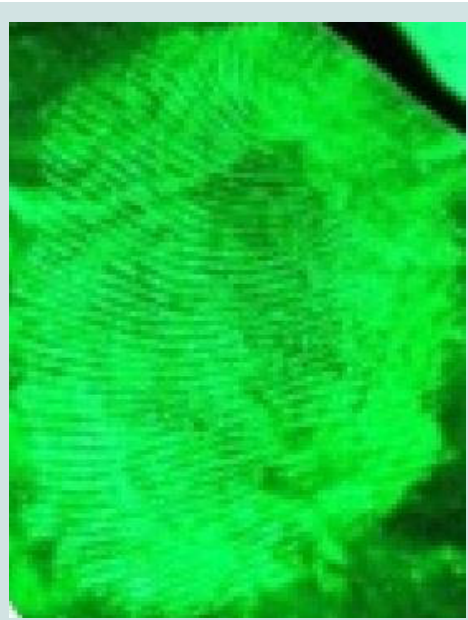

Figure 3: Latent fingerprints under fluorescence light by brilliant blue $R$ based composition 
Citation: Kapoor S, Gurvinder S. Sodhi, Kumar S. Spectroscopic and Photophysical Studies of Fingerprint Dusting Compositions. J Forensic Investigation. 2015;3(2): 4 .

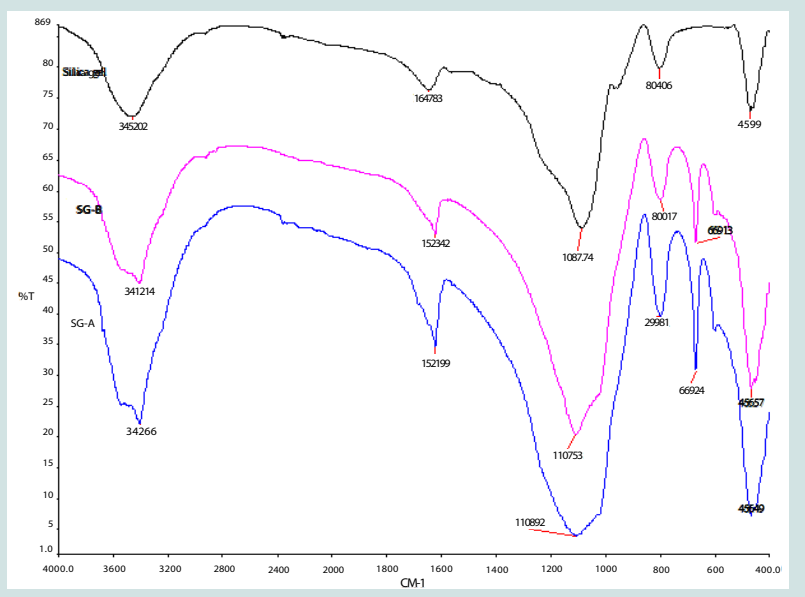

Figure 4: Comparison of FTIR spectra of the (A) silica gel, (B) SG-B and (C) SG-A with the vibrational modes of the Major Peaks

\section{fingerprints.}

\section{Conclusion}

On the basis of this investigation, we endeavoured to suggest that while formulating the fingerprint dusting powders, the degree of chemical interaction between the bonding material and the colorant should be taken into consideration. The level of interaction between these two broad components of a fingerprint composition, which might be gauged on the basis of spectral and photophysical studies, profoundly affected the quality of developed impressions. Thus, in the present case, better results obtained with brilliant blue $\mathrm{R}$ based composition may be attributed to a greater degree of interaction between the mixture and colorant, leading to greater fluorescent characteristics and oscillator strength of this formulation as compared the acridine orange based composition.

\section{References}

1. Sodhi GS, Kaur J (2001) Powder method for detecting latent fingerprints: a review. Forensic Sci Int 120: 172-176.

2. Thomas GL (1978) The physics of fingerprints and their detection. J Phys $E$ 11: $722-731$

3. Menzel ER, Fox KE (1980) Laser detection of latent fingerprints: preparation of fluorescent dusting powders and the feasibility of a portable system. $J$ Forensic Sci 25: 150-153.

4. Liu L, Zhang Z, Zhang L, Zhai $Y$ (2009) The effectiveness of strong afterglow phosphor powder in the detection of fingermarks. Forensic Sci Int 183: 45-49.

5. Ramotowski RS (2013) Lee and Gaensslen's advances in fingerprint technology, 3rd Ed., CRC Press, Boca Raton, p: 1-16.

6. Champod C, Lennard C, Margot P, Stoilovic M (2004) Fingerprints and other ridge skin impressions. CRC Press, Boca Raton, p: 136-138.

7. Sodhi GS, Kaur J, Garg RK (2004) Fingerprint powder formulations based on organic, fluorescent dyes. J Forensic Identification 54: 4-8.

8. Sodhi GS, Kaur J (2007) A novel, nanoparticle size fingerprint detecting composition based on fluorescent Lucifer $Y$ dye. Fingerprint Whorld 34: 2425.

9. SWGFAST, Standard for the Documentation of Analysis, Comparison, Evaluation, and Verification (ACE-V) (Latent), 2/12/10, version 1.0. Copyright (C) 1996-2013.

10. Swann GE, Patwardhan S (2010) Application of fourier transform infrared spectroscopy (FTIR) for assessing biogenic silica sample purity in geochemical analyses and palaeoenvironmental research. Clim Past Discuss 6: 1629-1653.

11. Bhatia S, Kaushik NK, Sodhi GS (1987) Organomercury (II) Dithiocarbazates: Synthesis characterization and biological studies. Inorganica Chimica Acta 127: 141-146.

12. Calvert JG, Pitts JN (1966) Photochemistry, Wiley, New York.

13. Rohtagi Mukherjee KK (1978) Fundamentals of photochemistry, WileyEastern, New Delhi.

\section{Acknowledgements}

The authors were grateful to the University Grants Commission, New Delhi for sanctioning a research project of which the present work was a part. 